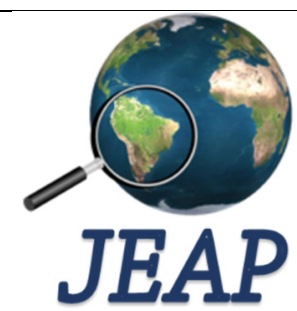

ISSN: 2525-815X

\section{Journal of Environmental} Analysis and Progress

Journal homepage: www.jeap.ufrpe.br/ http://dx.doi.org/10.24221/jeap.2.3.2017.1449.283-293

\title{
Aplicação de índice de vegetação no monitoramento da seca: Açude Algodões no
} Sertão pernambucano

\section{Application of vegetation index for drought monitoring: Algodões Reservoir in the Sertão of Pernambuco}

\author{
José Ráurium Bacalhau ${ }^{\mathrm{a}}$, Alfredo Ribeiro Neto ${ }^{\mathrm{a}}$, Leidjane Maria Maciel de Oliveira ${ }^{\mathrm{a}}$
}

${ }^{\text {a }}$ Universidade Federal de Pernambuco-UFPE, Departamento de Engenharia Civil, Av. da Arquitetura, s/n, Cidade Universitária, Recife-PE, Brasil. CEP: 50.740-550. E-mail: raurium@gmail.com ribeiront@gmail.com; leidjaneoliveira@hotmail.com.

\section{A R T I C L E I N F O}

Recebido 29 Jun 2017

Aceito 27 Jul 2017

Publicado 31 Jul 2017

\begin{abstract}
A B S T R A C T
The low annual precipitation rate is one of the key features in the Brazilian semiarid region. In particular, it is noted in this region a significant reduction of total rainfall after 2011, causing serious damages to the reservoir storage. The Algodões reservoir, main water source in Ouricuri municipality of Pernambuco State, has shown a considerable decreasing in its storage, was declared in collapse situation in 2016. This study aimed to analyze the water availability reduction using geoprocessing tools in the watershed of the Algodões reservoir. It was used Normalized Difference Vegetation Index-NDVI to inform about vegetation in the watershed between 2011 and 2016, as well as high-resolution images to identify the reduction in water surface of the reservoir between 2011 (a year with precipitation near to the annual average) and 2016 (five years after the drought beginning). Hydrometeorological data helped to verify that periods with negative deviations from the mean rainfall coincided with the reduction in reservoir volume.
\end{abstract}

Keywords: Water resource, rainfall, semi-arid.

\section{R E S U M O}

O baixo índice pluviométrico é uma das principais características da região Semiárida do Brasil. Em particular, verifica-se nesta região uma redução significativa dos totais pluviométricos a partir do ano de 2011, ocasionando sérios danos aos níveis dos reservatórios. O açude Algodões, principal fonte hídrica para o município de Ouricuri Pernambuco, vem apresentando uma queda considerável em seu volume, onde em 2016 foi declarado em situação de emergência. Fazendo uso de ferramentas de geoprocessamento, objetivou-se analisar o real cenário da área incremental da microbacia do açude Algodões. Utilizou-se o Índice de Vegetação por Diferença Normalizada-NDVI para obter informações sobre a vegetação na área de estudo entre 2011 e 2016, além de imagens de alta resolução para identificar a redução na lâmina d'água do açude entre os anos de 2011 (ano médio normal) e 2016 (ano de seca). Dados hidrometeorológicos auxiliaram a perceber que os períodos com desvios negativos à pluviometria média climatológica coincidiram com a redução no volume do açude.

Palavras-Chave: Recurso hídrico, pluviometria, semiárido.

\section{Introdução}

A seca, enquanto fenômeno natural, pode ser entendida como uma deficiência de precipitação durante um período prolongado de tempo que resulta em escassez de água para algumas atividades, grupo ou setor ambiental (NDMC, 2006), sendo um importante indicador para investimentos no gerenciamento e gestão dos 
recursos hídricos. Seu monitoramento é imprescindível para mitigar os impactos negativos da variabilidade climática e propor medidas apropriadas a cada fase de agravamento.

No entanto, dada a complexidade do fenômeno, tais medidas, não são de fácil implementação, sobretudo quando desde 2011 a seca tem castigado o semiárido nordestino, culminando em 2013 na pior seca dos últimos 50 anos, segundo o relatório climático da Organização Meteorológica Mundial (WMO, 2014).

No Sertão Pernambucano a situação não foi diferente, fortemente impactada pelos efeitos negativos da seca, a população sofre com a ausência do recurso hídrico. Torna-se, assim, um desafio permanente aos municípios atingidos conviverem com esse desastre natural. Em particular, o município de Ouricuri, que tem como principais atividades, a cultura de subsistência e a pecuária extensiva, ambas necessitam do açude de Algodões como principal manancial de atendimento às suas demandas.

Uma das ferramentas que tem se apresentado ao estudo da problemática da seca é o Sensoriamento Remoto (SR). Esta tecnologia, dentre outros usos, detecta alterações na cobertura do solo e presença de água, proporcionando através de índices de vegetação, o diagnóstico e planejamento socioambiental. O SR constitui uma solução de baixo custo e abrangência de grandes áreas geográficas e registros temporais.

No estudo da seca, destaca-se o uso do Índice de Vegetação por Diferença Normalizada (Normalized Difference Vegetation Index-NDVI), que se trata de um índice obtido a partir de dados espectrais para explicitar as condições vegetativas, ou seja, o vigor vegetativo em cada pixel da imagem de forma numérica, variando de -1 a 1 (Albuquerque et al., 2015).

Diante do exposto, objetivou-se analisar as condições de seca referentes aos anos 2011 e 2016 em Ouricuri-PE, mediante estudo da área de drenagem incremental do Açude Algodões, com base em dados geográficos e hidrometeorológicos.

\section{Material e Métodos}

A área de drenagem incremental do açude Algodões situa-se em sua maior parte no município de Ouricuri, que se encontra a uma altitude média de 434 metros e distante cerca de $630 \mathrm{~km}$ da capital Pernambucana, Recife. Limitase ao norte com os municípios de Araripina, Trindade e Ipubi. Ao sul, com Santa Cruz e Santa Filomena, a leste com Parnamirim e Bodocó e a oeste com o Estado do Piauí. O clima é do tipo tropical quente semiárido, enquadrando-se na classificação climática de Köppen e Geiger como BSh. A precipitação pluviométrica média anual é de $630 \mathrm{~mm}$ e temperatura média anual de $24,7^{\circ} \mathrm{C}$. De acordo com as estimativas populacionais do IBGE, o município possuía 67.676 habitantes no ano de 2015. Na Figura 1 pode-se observar a cena de uma das imagens de estudo (Imagem RapidEye com composição 3R2G1B), com a localização do município de Ouricuri e a área incremental da microbacia do açude Algodões, juntamente com a sua rede de drenagem e as estações pluviométricas utilizadas no estudo (APAC, 2017).

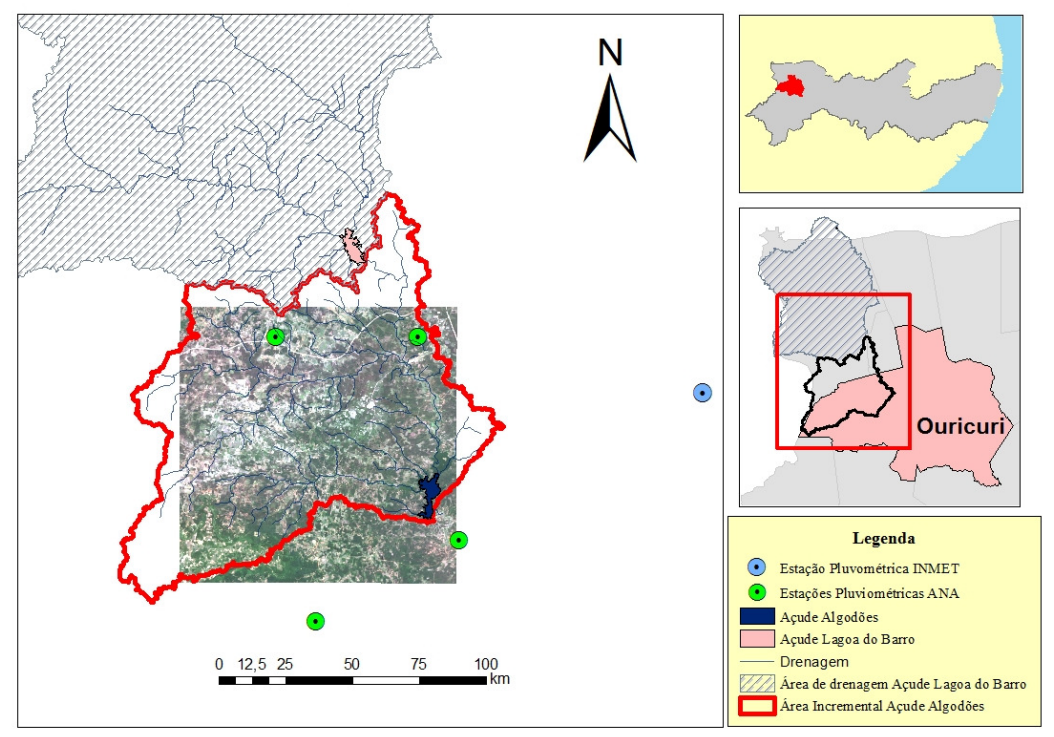

Figura 1. Localização da bacia incremental do açude Algodões, em Ouricuri-PE. 
A cidade faz parte da região de desenvolvimento do Araripe e a agricultura é a atividade econômica predominante produzindo feijão, algodão herbáceo, mandioca, mamona, milho, cebola e tomate. O rebanho de bovinos, a criação de aves e a pequena mineração são outras fontes de renda do município. Para suprir as necessidades hídricas da região existem dois reservatórios em Ouricuri: o Engenho Camacho voltado para o abastecimento humano de Bodocó e o Açude Algodões, principal reservatório do município, cujas águas são utilizadas para diversos fins, tais como consumo humano e irrigação. As atividades econômicas no entorno do reservatório geram alguns impactos que precisam ser identificados e mensurados para fins de preservação, o que é uma das demandas locais para uma gestão ambiental eficiente.
O Açude Algodões intercepta o riacho São Pedro, afluente do rio Brígida, e sua bacia hidrográfica possui $2.187 \mathrm{~km}^{2}$. A montante do Açude Algodões existem quatro reservatórios que controlam $1.542 \mathrm{~km}^{2}$ da sua área de drenagem. Como esse estudo visa entender a relação entre o vigor vegetativo e os cenários de seca no entorno do reservatório, será analisada a área de drenagem incremental entre os reservatórios Algodões e Lagoa do Barro, através dos dados geográficos de duas imagens de satélite com $614 \mathrm{~km}^{2}$, onde se situa o espelho d'água do reservatório.

O Açude Algodões possui uma capacidade máxima de $58.481 .874 \mathrm{~m}^{3}$ e teve seu volume hídrico diminuído, significativamente, desde o ano de 2011, principalmente devido à redução das chuvas na região. A Figura 2 mostra a precipitação mensal média relativa aos dois períodos investigados: 1933-2010 e 2011-2015.

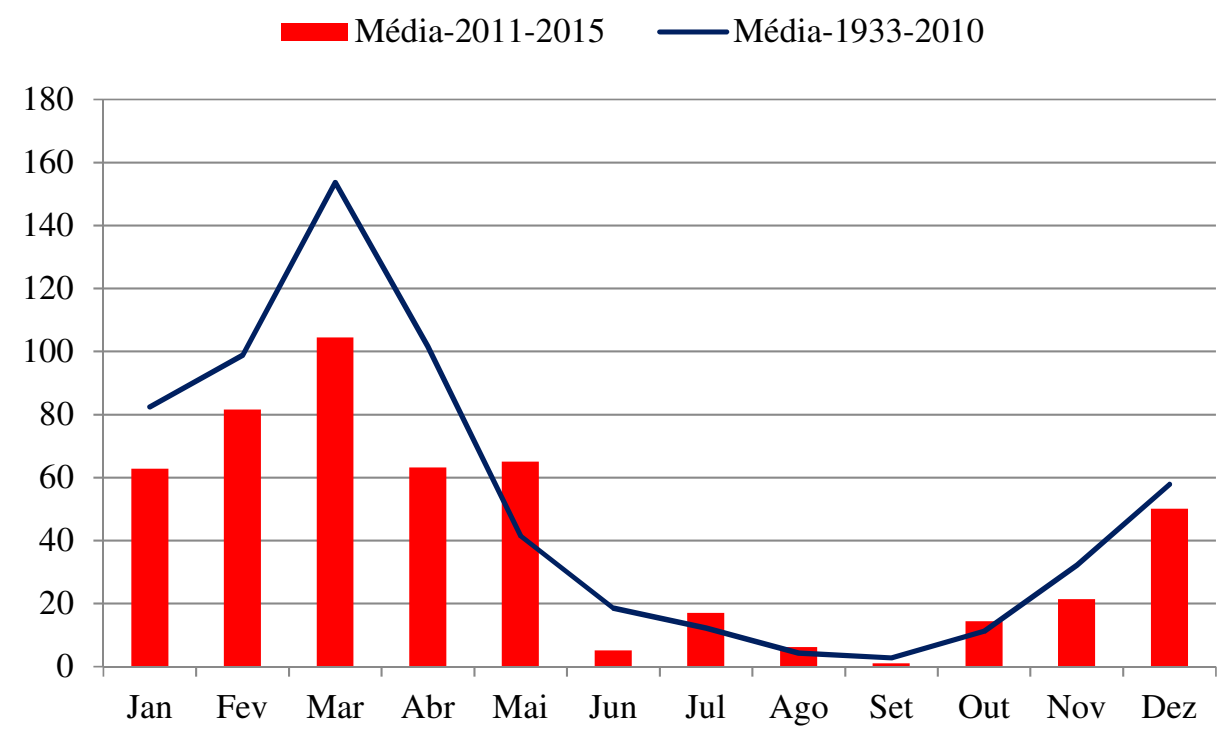

Figura 2. Precipitação mensal média extraída das estações pluviométricas utilizadas no estudo (estações da Tabela 3). Fonte: Bacalhau, J.R. (2017)

O aplicativo de Sistema de Informação Geográfica (SIG) utilizado foi o ArcGis (ESRI), permitindo a utilização de ferramentas de geoprocessamento para o recorte de dados, álgebra de mapas e produção do layout dos mapas finais, bem como a utilização de suas ferramentas de modelagem (hydrology) para a execução de algoritmos voltados à hidrologia e geomorfologia. Para o processamento das imagens de satélite, visando a extração dos índices de vegetação, foi utilizado o Erdas Imagine (Leica).
Os dados geográficos utilizados foram: imagem de satélite RapidEye, fornecida pelo Ministério do Meio Ambiente, e imagem Landsat 8 OLI, bem como arquivos vetoriais do tipo "shape" representativos dos limites municipais e estaduais.

As imagens foram adquiridas ortorretificadas (nível 3A para Rapideye, e nível 1 para Landsat 8), com as características descritas na Tabela 1.

Tabela 1. Características das imagens ortorretificadas (nível 3A para Rapideye, e nível 1 para Landsat 8)

\begin{tabular}{lll}
\hline Características & RapidEye & LandSat 8 OLI \\
\hline Data de Aquisição & $25 / 06 / 2011$ & $22 / 05 / 2016$ \\
Número de Bandas & 5 & 11 \\
Resolução Espectral & $0,44 \mu \mathrm{m} \mathrm{e} 0,85 \mu \mathrm{m}$ & $0,43 \mu \mathrm{m}$ a $12,51 \mu \mathrm{m}$
\end{tabular}


Resolução Radiométrica

Resolução Temporal

Resolução Espacial

Escala Compatível
12 bits

1 dia (off-nadir) e 5,5 dias (nadir)

$5 \mathrm{~m}$ (após ortorretificação)

$1: 25.000$
12 bits

16 dias

$30 \mathrm{~m}$ (multiespectral) / 15 (pancromática) $1: 100.000$
A extração das características físicas e delimitação das bacias foram determinadas a partir do modelo Numérico de Terreno (MNT), com resolução espacial de $90 \mathrm{~m}$, obtidos através da missão Shuttle Radar Topography Mission (SRTM) criado com o objetivo de obter informações altimétricas da superfície terrestre, gerando uma base para estudos espaciais diversos.

Para subsidiar os estudos de seca também foi imprescindível o uso de dados hidrometeorológicos, tais como pluviométricos e limnimétricos. Em Pernambuco, o órgão responsável pelo monitoramento hidrometeorológico é a Agência Pernambucana de Águas e Clima (APAC), que conta com uma rede de estações convencionais e automáticas no Estado e disponibiliza os dados coletados na internet (http://www.apac.pe.gov.br). Também foi utilizada a base de dados disponibilizada pela Agência Nacional de Águas (ANA) através de seu Hidroweb e o Banco de Dados Meteorológicos para Ensino e Pesquisa (BDMEP) do Instituto Nacional de Meteorologia (INMET).

O processamento das imagens RapidEye se deu em conformidade com Ponzoni, Shimabukuro \& Kuplich (2012): calibração radiométrica que corresponde à obtenção da radiância espectral de cada banda, de acordo com a Equação 1 (Blackbridge, 2015); obtenção da reflectância monocromática (Equação 2); e cômputo do Índice de Vegetação por Diferença Normalizada (Normalized Difference Vegetation Index - NDVI), aplicando a Equação 3 (Rouse et al., 1974).

$$
R A D(i)=D N * 0,01
$$

onde $\mathrm{RAD}(\mathrm{i})$ é a radiância espectral de cada banda, DN é o nível digital, e 0,01 é o fator de escala radiométrica dado por Blackbridge (2015).

$$
\rho(i)=R A D(i) * \frac{\pi * \text { SunDist }^{2}}{E A I(i) * \cos (\text { SolarZenit })}
$$

onde $\rho$ i é a reflectância monocromática; RAD(i) é o valor da radiância espectral de cada banda; SunDist é a distância Terra-Sol em Unidades Astronômicas (UA); EAIi é a irradiância da exoatmosfera, segundo Blackbridge (2015); SolarZenith é o ângulo zenital solar, fornecido nos metadados da imagem.

$$
N D V I=\frac{\rho_{N I R}-\rho_{R E D}}{\rho_{N I R}+\rho_{R E D}}
$$

onde NDVI é o Índice de Vegetação por Diferença Normalizada; $\rho_{\text {RED }}$ é a reflectância na banda do vermelho; e $\rho_{\text {NIR }}$ é a reflectância na banda do infravermelho próximo. Conforme Ponzoni, Shimabukuro \& Kuplich (2012), valores negativos de NDVI correspondem a água; valores muito próximos de 0 correspondem a superfície não vegetada; e quanto mais próximo de 1 , mais densa é a vegetação.

O processamento das imagens Landsat 8 OLI se deu em conformidade com Ruhoff, Silva \& Rocha (2015): para converter os valores quantizados e calibrados (ND) do sistema sensor Landsat 8 OLI para reflectância espectral, utilizou-se coeficientes radiométricos disponibilizados no arquivo de metadados das imagens. Maiores detalhes podem ser obtidos em USGS (2016).

A reflectância planetária no topo da atmosfera ( $\left.\rho^{\prime} \lambda\right)$ é calculada a partir da Equação 4.

$\rho^{\prime} \lambda=M \rho Q \operatorname{cal}+A \rho$

onde $\rho^{\prime} \lambda$ não apresenta correção para o ângulo solar. M $\rho$ corresponde ao fator multiplicativo de reescalonamento para cada banda (disponível nos metadados da imagem), Qcal o número digital para cada pixel e A $\rho$ corresponde ao fator aditivo de reescalonamento para cada banda (disponível nos metadados da imagem). Para corrigir a reflectância em função do ângulo solar e da distância astronômica Terra-Sol (d) foi usada a Equação 5.

$$
\rho \lambda=\frac{\rho^{\prime} \lambda}{\cos (\theta s z) \frac{1}{d^{2}}}=\frac{\rho^{\prime} \lambda}{\sin (\theta s e) \frac{1}{d^{2}}}
$$

onde $\rho \lambda$ corresponde a reflectância planetária no topo da atmosfera corrigida, $\theta_{\mathrm{SE}}$ corresponde ao ângulo de elevação solar (disponível nos metadados da imagem) e $\theta_{\mathrm{sZ}}$ corresponde ao ângulo zenital solar local (calculado a partir de $\theta_{\mathrm{SZ}}$ $\left.=90^{\circ}-\theta_{\mathrm{SE}}\right)$.

O cálculo do NDVI se deu em conformidade com a Equação 3, utilizando as 
bandas $\rho_{\text {RED }}$ e $\rho_{\text {NIR }}$, resultantes da reflectância corrigida pela Equação 5.

Através das imagens NDVI foi realizada uma classificação multiespectral, a qual classificou a região em áreas com vegetação, solo exposto e corpos hídricos. As áreas com vegetação foram classificadas segundo Chagas et al. (2008), onde a densidade da cobertura vegetal foi dividida em quatro fitofisionomias (Tabela 2), seguindo a metodologia de Lourenço \& Landim (2004), onde os valores mais altos de NDVI foram associados a uma maior densidade de cobertura vegetal.

Tabela 2. Valores de Índice de Vegetação por Diferença Normalizada-NDVI utilizados na seleção de classes de cobertura vegetal (Chagas et al., 2008).

\begin{tabular}{ll}
\hline Classe & NDVI \\
\hline Água & $<-0,1$ \\
Solo exposto & 0,01 a 0,1 \\
Vegetação rala & 0,1 a 0,2 \\
Vegetação esparsa & 0,2 a 0,4 \\
Vegetação de transição & 0,4 a 0,6 \\
Vegetação densa & $>0,6$ \\
\hline
\end{tabular}

No presente estudo, para definição da pluviometria média na área de estudo, foi utilizado o processo de Thiessen para cálculo da chuva média através de postos indicados pela ANA, aqueles que foram produto de uma análise de consistência e preenchimento de falhas realizados por esta instituição por ocasião do Atlas Nordeste (ANA, 2006), que resultou, em sua maioria, em séries com um período uniforme de
69 anos (1933 a 2001). Para o período de 2002 a 2016 foi utilizado um posto pluviométrico do INMET em Ouricuri, como sendo representativo da precipitação média estendida, haja vista que para o período de 1976 a 1984, este posto apresentou uma boa correlação $(0,85)$ em relação à precipitação média calculada. A Tabela 3 mostra a descrição das estações utilizadas.

Tabela 3. Estações pluviométricas em Pernambuco, Brasil.

\begin{tabular}{lcrrcc}
\hline Código & $\begin{array}{c}\text { Base de } \\
\text { dados }\end{array}$ & Latitude & Longitude & Nome do posto & Período \\
\hline 740016 & ANA & $-7,833$ & $-40,333$ & Barra de São Pedro (Manaca) & $1933-2001$ \\
740020 & ANA & $-7,833$ & $-40,450$ & Nascente (Olho D'água) & $1933-2001$ \\
840002 & ANA & $-8,000$ & $-40,300$ & Açude Jatobá & $1933-2001$ \\
840024 & ANA & $-8,006$ & $-40,416$ & Varginha & $1933-2001$ \\
82753 & INMET & $-7,9$ & $-40,04$ & Ouricuri & $1976-2016$ \\
\hline
\end{tabular}

\section{Resultados}

Através das imagens do NDVI observa-se que entre aquelas datadas de junho de 2011 e maio de 2016 foi encontrado o decaimento do NDVI na área incremental da microbacia do Açude Algodões (Figura 3).

De acordo com o NDVI apresentado, os tons de verde mais escuro (acima de 0,46), correspondem à vegetação vigorosa, enquanto os valores negativos correspondem à água. $\mathrm{Na}$ imagem de 25/06/2011, percebe-se uma maior presença de vegetação sobre a área, especialmente no sudoeste da área de estudo. Os tons azuis indicam a presença de água, a perceber pela localização do açude Algodões.

O histograma (Figura 4a) dessa mesma imagem apresentou em sua estatística um NDVI médio de 0,42 , indicando maior concentração de pixels em dois intervalos característicos do vigor vegetativo, compreendendo os valores entre $0,30 \mathrm{e}$ 0,60 , sendo o pico em, aproximadamente, 0,48 com mais de 900 mil pixels. 


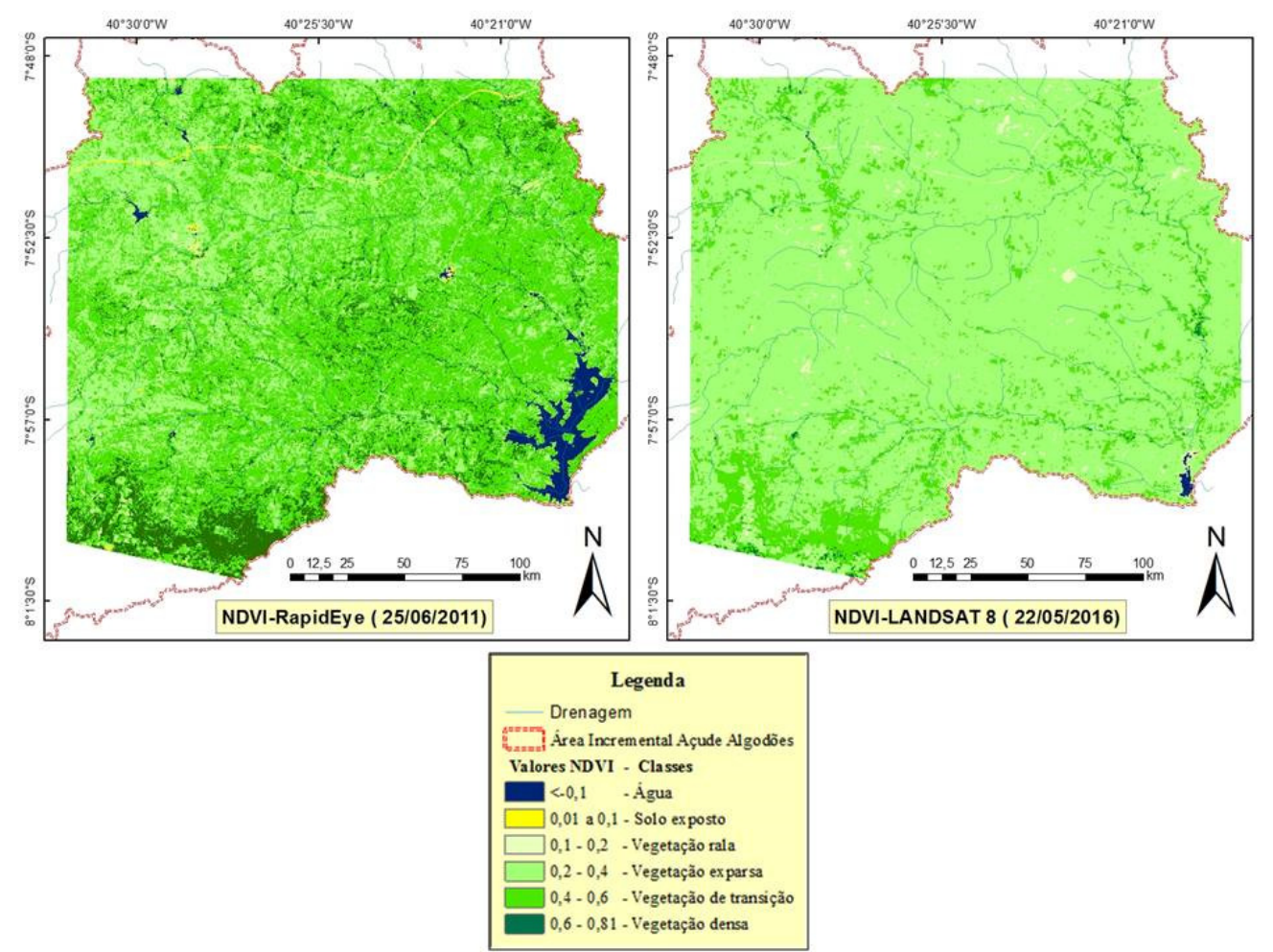

Figura 3. Imagens de Índice de Vegetação por Diferença Normalizada-NDVI da área incremental da microbracia do Açude Algodões.

A imagem relativa ao dia 22/05/2016 mostrou menor presença de vegetação considerada vigorosa apresentando maior frequência dos valores de NDVI intermediários $(0,10$ a 0,46$)$ sobre a microbacia, inclusive diminuindo a presença de pixels indicadores de presença de água, entre $-0,24$ e $-0,01$. A zona sudoeste da microbacia permaneceu como a de maior concentração de vegetação, apesar de ter se reduzido sensivelmente. No histograma dessa imagem (Figura 4b) a média do NDVI $(0,30)$ ficou $27 \%$ inferior em relação à imagem de 2011, confirmando-se a interpretação visual de decaimento no NDVI, visto que há frequências distribuídas de modo menos discrepante dos pixels com valores entre 0,20 e 0,40 . (a)

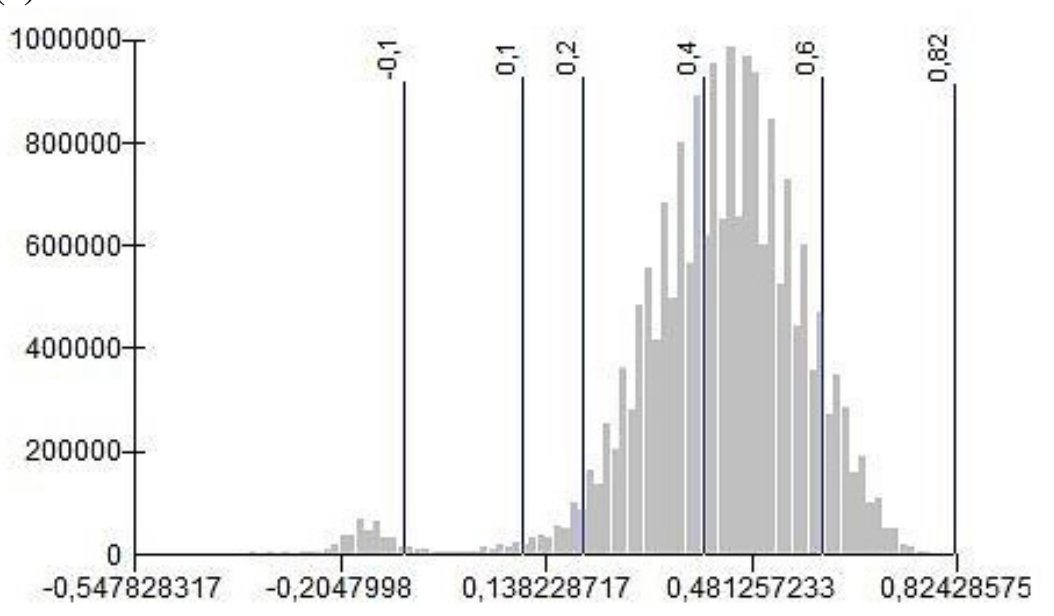

Classification Statistics

\begin{tabular}{|lr|}
\hline Count: & 19125105 \\
Minimum: & $-0,547828317$ \\
Maximum: & 0,829687774 \\
Sum: & $8.189,411,518$ \\
Mean: & 0,428202173 \\
Standard Deviation: & 0,147615568 \\
\hline
\end{tabular}


(b)

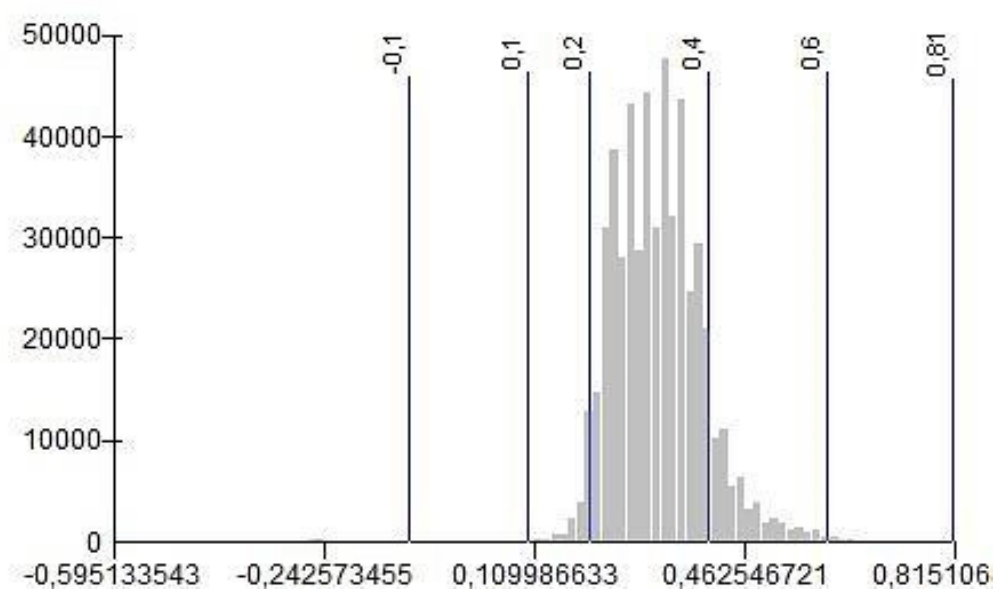

Classification Statistics
\begin{tabular}{|lr|}
\hline Count: & 551184 \\
Minimum: & $-0,595133543$ \\
Maximum: & 0,815106809 \\
Sum: & $168.871,8821$ \\
Mean: & 0,306380233 \\
Standard Deviation: & 0,095678988 \\
\hline
\end{tabular}

Figura 4. Histograma e estatísticas das imagens (a) RapidEye e (b) Landsat 8.

Em uma análise dos histogramas da Figura 4, a fim de observar as questões relacionadas à desertificação, foi levantada a

distribuição dos pixels do NDVI das imagens estudadas, resultando na Figura 5.

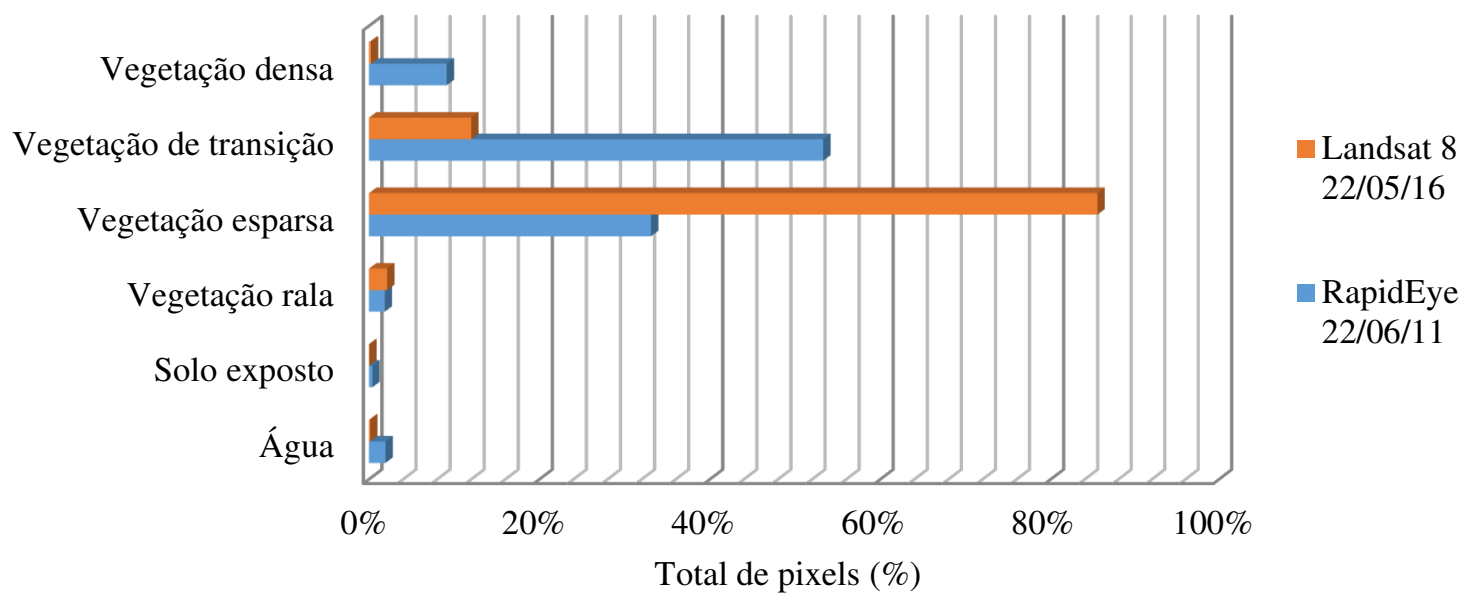

Figura 5. Distribuição percentual dos pixels por cobertura vegetal do histograma.

Percebe-se na Figura 5 uma movimentação significativa das classes de NDVI contidas no intervalo de 0,2 a 0,81 (vegetação esparsa a densa), onde em 22/06/2011 o NDVI das vegetações densa, transição e esparsa encontravam-se distribuídas com 9, 53 e $33 \%$, respectivamente. Em 22/05/2016 houve uma redução importante do NDVI das coberturas densa (de $9 \%$ para $0,23 \%$ ) e de transição (de $53 \%$ para
12\%) com aumento significativo da esparsa (de $33 \%$ para $85 \%$ ).

A Figura 6 mostra, para o período compreendido entre janeiro de 2010 e abril de 2016, os desvios da pluviometria mensal com relação à precipitação média histórica calculada para a área de estudo. $\mathrm{O}$ cálculo dos desvios se deu pela subtração da precipitação do mês e a precipitação média histórica calculada para o mês. 


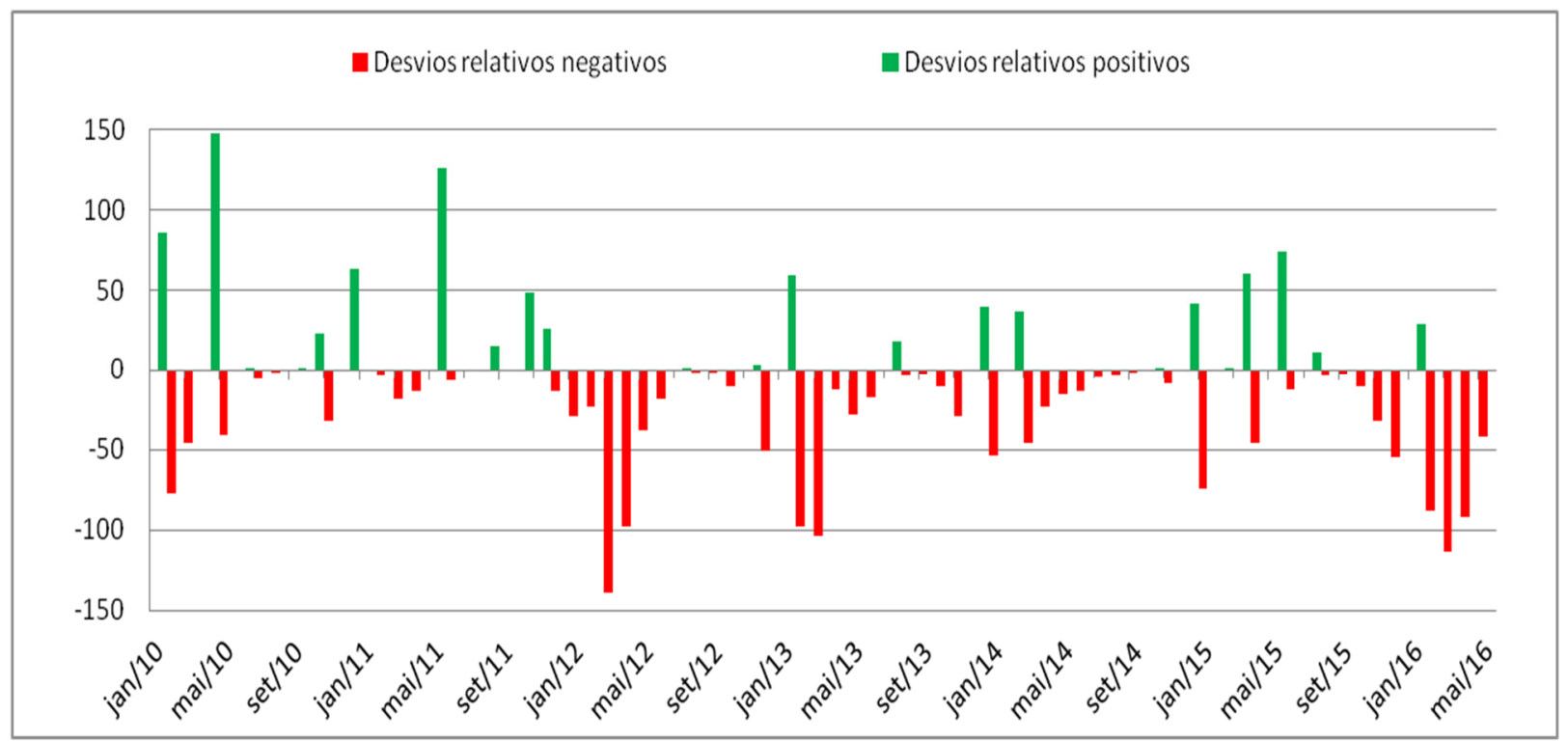

Figura 6. Desvio da precipitação (mm) relativo ao período 2010 a 2016.

As barras na cor vermelha indicam os meses em que a chuva foi menor que a climatologia daquele mês. Observa-se que, ao longo de todo o período analisado, foram poucos os meses que apresentaram chuvas acima da média (cor verde). Logo, é nítida a predominância de meses com chuva abaixo da média, de modo que os desvios mais críticos ocorreram em março de 2012 e 2016 (desvios de $-138,77$ e $-114,07$ $\mathrm{mm}$, respectivamente). No entanto, a partir de novembro de 2015 os desvios negativos foram intensos e constantes, não restando dúvida quanto à seca instalada na região, impactando significativamente a vegetação.

A chuva tem forte influência sobre a recarga hídrica dos reservatórios. A escassez de chuvas, que por sua vez ocorre desde o inicio do ano de 2011, tem afetado consideravelmente o volume do açude Algodões. Na Figura 7 é evidente o contraste entre as áreas do espelho d'água em junho de 2011 e maio de 2016, apresentando aproximadamente $10.303 .380 \mathrm{~m}^{2}$ e $422.730 \mathrm{~m}^{2}$, respectivamente.
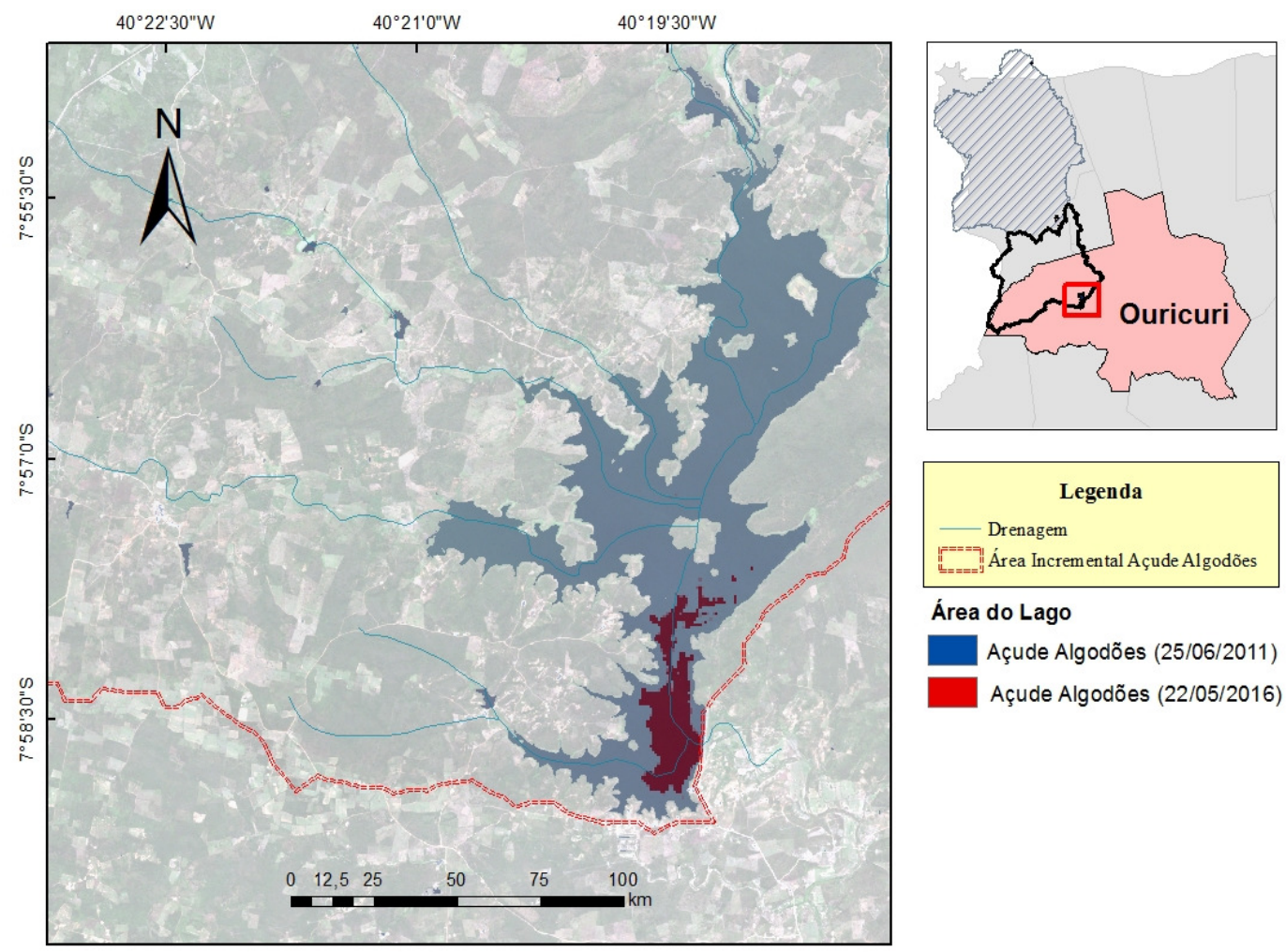

Área do Lago

Açude Algodões (25/06/2011)

Açude Algodões (22/05/2016)

Figura 7. Área de superfície hídrica do Açude Algodões em 06/2011 e 05/2016. 
Na Figura 8 são apresentados os registros do volume do açude Algodões de janeiro 2011 a março de 2016. Nesse período, o açude atingiu sua capacidade máxima em março de 2011, com $90,65 \%$ do volume útil. Desde então houve um decaimento contínuo até março de 2016, reduzindo o volume de $53 \mathrm{hm}^{3}$ para $0,74 \mathrm{hm}^{3}$, correspondente a $1,2 \%$ da capacidade máxima do açude.
O padrão das chuvas no Sertão pernambucano é caracterizado anualmente pelas estações seca e chuvosa, conforme Figura 2. Em Ouricuri, normalmente, maio é o mês que mais chove e isso coincide com os maiores volumes hídricos do açude. Após uma queda contínua de 2011 até 2014, houve uma discreta recuperação a partir de fevereiro de 2014 até dezembro de 2015, seguido por nova queda em 2016, estando em junho deste ano completamente em colapso.

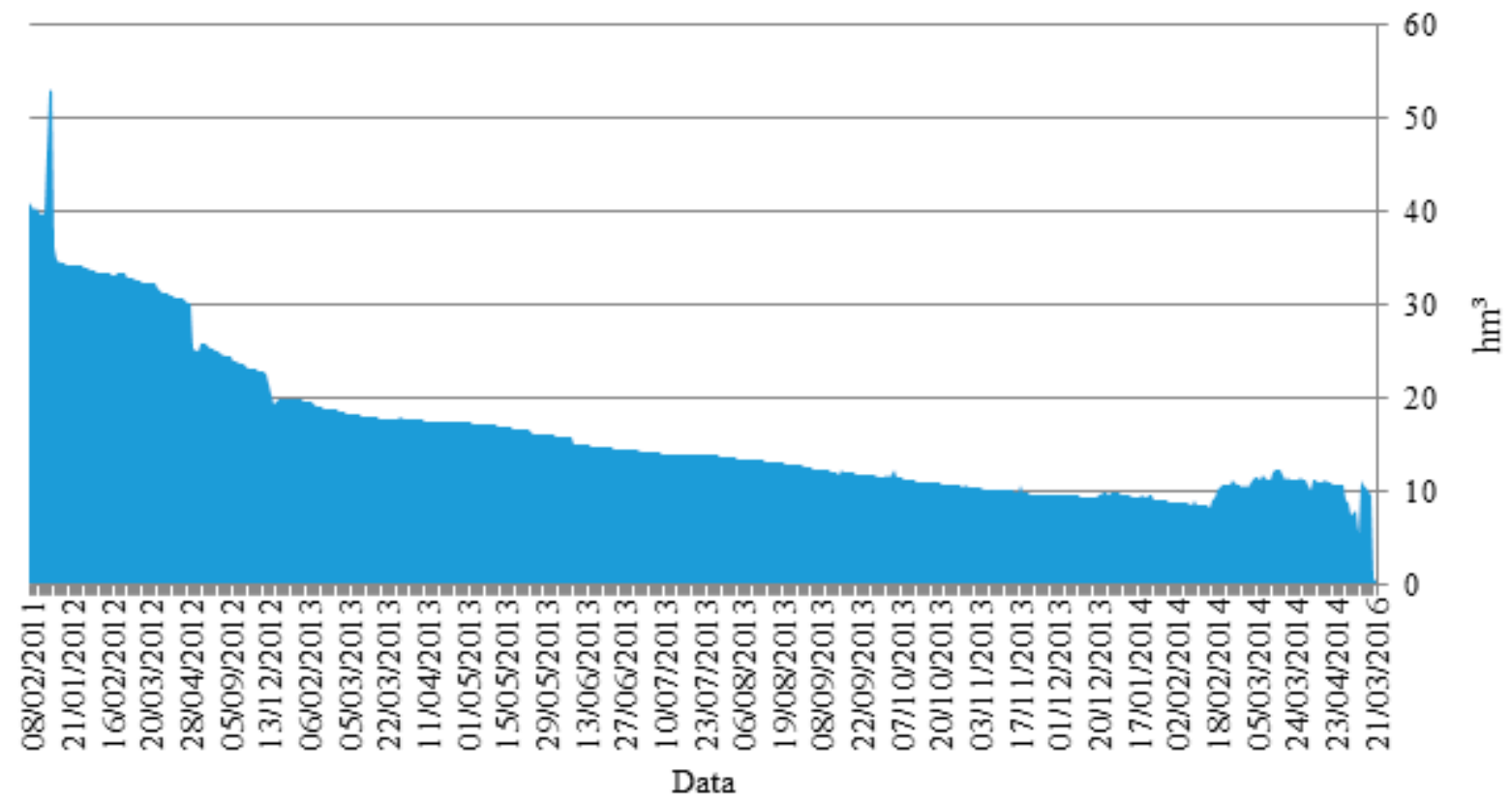

Figura 8. Volume (hm³) do açude Algodões entre 2011 e 2016. Fonte: APAC (2017).

$\mathrm{Na}$ data deste estudo, a situação do açude Algodões se mostrou bastante preocupante para a gestão pública e para a população. A captação de água no açude foi inviável devido ao seu baixo nível e a solução temporária para dar sequência ao abastecimento para a população, adotada pela gestão municipal, foi a aquisição de caixas d'água e contratação de carros pipa. Em outras esferas administrativas existem medidas previstas para serem executadas, a exemplo da transposição do Rio São Francisco.

\section{Discussão}

Um intervalo de cinco anos implicou em um decaimento significativo do NDVI na área de estudo, implicando, ao longo do tempo, em uma série de impactos ambientais, como a erosão superficial e a desertificação, de acordo com Rios \& Vale (2014) e Silva \& Machado (2014).

A avaliação da variação temporal da cobertura vegetal mostrou clara alteração das classes do NDVI no sentido da redução do vigor vegetativo, mostrando os efeitos da seca e alertando quanto à desertificação. Este fato corrobora Garcia et al. (2008) e Accioly et al.
(2001), quando avaliam que os índices de vegetação, temperatura e emissividade, albedo e fluxo de calor no solo são parâmetros que devem ser observados na avaliação de risco à desertificação.

De outro modo, o NDVI também pode ser utilizado para gerar índices de seca, que pode ser percebida a partir da anomalia do índice ao longo do tempo, tal como em Moreira et al. (2015).

Uma das causas para o declínio do NDVI é a falta de chuvas, visto que a água é um elemento fundamental para a saúde da vegetação (considerando as especificidades das espécies), que por sua vez dependem da localização e do clima da região (Albuquerque et al., 2015). De acordo com os resultados obtidos por Ávila et al. (2009) para a região sudeste, a vegetação respondeu em, aproximadamente, 15 dias após a ocorrência de precipitação. Na região semiárida do Nordeste, Albuquerque et al. (2014) encontraram significativa mudança no NDVI entre os períodos seco e chuvoso.

A perda do vigor vegetativo está associada ao déficit prolongado de precipitação, contribuindo com o risco à desertificação na área 
de estudo, provocando uma situação calamitosa do açude Algodões, que se encontrava com apenas 1,2\% da capacidade total em março de 2016. Nesse contexto, torna-se indispensável a busca por medidas alternativas para o abastecimento de água à população de Ouricuri.

\section{Conclusão}

A utilização de apenas duas imagens de satélite, com características e resoluções distintas, permite a obtenção do NDVI variando no espaço e no tempo, proporcionando uma comparação qualiquantitativa das imagens. Os histogramas das imagens NDVI e os dados hidrometeorológicos atestaram os efeitos impactantes de 5 anos de seca na região.

As situações de seca são fenômenos naturais e previsíveis. O sensoriamento remoto se apresenta, não só como instrumento de análise para diagnóstico, mas, também, pode e deve ser utilizado como ferramenta de planejamento, permitindo mitigar os impactos socioeconômicos relacionados à escassez hídrica, promovendo uma relação mais equilibrada de convivência com a seca.

\section{Agradecimentos}

Os autores agradecem à Agência Pernambucana de Águas e Clima (APAC); ao Instituto Nacional de Ciência e Tecnologia (INCT) - Observatório Nacional da Dinâmica da Água e de Carbono no Bioma Caatinga (ONDACBC), Convênios CAPES 88887.136369/2017-00 e CNPq 465764/2014-2.

\section{Referências}

ACCIOLY, J. L. O.; OLIVEIRA, M. A. J.; SILVA, F. H. B. B.; BURGOS, M. 2001. Avaliação de Mudanças no Albedo do Núcleo de Desertificação do Seridó através de Imagens do Landsat TM. Anais X Simpósio Brasileiro de Sensoriamento Remoto-SBSR, Foz do Iguaçu, PR, Brasil, INPE. pp. 549-556.

ALBUQUERQUE, E. M.; ANDRADE, S. C. DE P.; MORAIS, H. F. DE; DINIZ, J. M. T.; SANTOS, C. A. C. DOS. 2014. Análise do comportamento do NDVI e NDWI sob diferentes intensidades pluviométricas no município de Sousa-PB. Revista Estudos Geoambientais. v. 01, n. 01 Disponível em: http://periodicos.ufpb.br/index.php/geo/article/vie w/17986/10625. Acesso em: 10 set. 2016.

ALBUQUERQUE, E. M. DE; DINIZ, J. M. T.; LIMA, R. F. DE; FERREIRA, F. N.; CHAGA SILVA, F. DAS. 2015. Técnicas de geoprocessamento no suporte à análise da seca na microbacia do açude Jatobá II. Revista Verde (Pombal-PB-Brasil), n. 4, p. 27-33.

ANA-Agência Nacional de Águas (Brasil). 2006. Atlas Nordeste-Abastecimento Urbano de ÁguaMinistério do Meio Ambiente; Superintendência de Planejamento de Recursos Hídricos-SPR. Brasília-DF.

APAC-Agência Pernambucana de Águas e Clima. Disponível em: http://www.apac.pe.gov.br. Acesso em: 3 de setembro de 2015.

ÁVILA, A. M. H. DE; GONÇALVES, R. R. DO V.; PINTO, H. S.; ZULLO JUNIOR, J. 2009. Relação entre a precipitação e o NDVI em imagens AVHRR/NOAA para a cana-de-açúcar, no estado de São Paulo. Anais Online do XIV Simpósio Brasileiro de Sensoriamento Remoto. Natal, Brasil, INPE. pp. 553-560.

BLACKBRIDGE. 2015. Satellite Imagery Product Specifications, Version 6.1, abril.

CHAGAS, M. DAS G. S. DAS.; GALVÍNCIO, J. D.; PIMENTEL, R. M. DE M. 2008. Avaliação da dinâmica espectral da vegetação de Caatinga em Arcoverde, Pernambuco. Revista de Geografia, v. 25 , n. 2, p. 45-60.

GARCÍA, M.; OYONARTE, C.; VILLAGARCÍA, L.; CONTRERAS, S.; DOMINGO, F.; PUIGDEFÁBREGAS, J. 2008. Monitoring land degradation risk using ASTER data: The non-evaporative fraction as an indicator of ecosystem function. Remote Sensing of Environment, v. 112, p. 3720-3736.

LOURENÇO, R. W.; LANDIM, P. M. B. 2004. Estudo da variabilidade do "Índice de Vegetação por Diferença Normalizada/NDVI" utilizando krigagem indicativa. Holos Environment, v. 4, n. 1, p. 38-55.

MOREIRA, A. A.; GUASSELLI, L. A.; SILVA FILHO, L. C. P. DA; ANDRADE, A. C. F. DE; ARRUDA, D. C. DE. 2015. Índice de Condição de Vegetação (VCI) para mapeamento de seca no Norte do Estado de Minas Gerais. Anais Online do XVII Simpósio Brasileiro de Sensoriamento Remoto, João Pessoa, PB, Brasil, INPE. pp. 16861692.

NDMC-National Drought Mitigation Center. 2006. What is drought? Undertanding and defining drought. University of Nebraska-Lincoln. 
PONZONI, F. J.; SHIMABUKURO, Y. E.; KUPLICH, T. M. 2012. Sensoriamento Remoto da Vegetação. 2 Ed. atualizada e revisada. ISBN: 978-85-7975-053-3. São Paulo: Oficina de Textos.

RIOS, I. Q.; VALE, R. DE M. C. DO. 2014. NDVI como subsídio para o estudo do processo de desertificação na bacia hidrográfica do Rio Vaza-Barris-Bahia. Anais Online do Simpósio Regional de Geoprocessamento e Sensoriamento Remoto-Geonordeste. Aracaju, SE, Brasil, INPE. pp. 495-500.

ROUSE, J. W.; HAAS, R. H.; SCHELL, J. A; DEERING, D. W. 1974. "Monitoring vegetation systems in the great plains with ERTS", Proceedings, Thrid Earth Resources Technology Satellite-1 Symposium, Greenbelt: NASA SP-351, pp. 3010-3017.

SILVA, V. C. B.; MACHADO, P. DE S. 2014. SIG na análise ambiental: susceptibilidade erosiva da bacia hidrográfica do córrego Mutuca, Nova Lima-Minas Gerais. Revista de Geografia. v. 31, n. 2, p. 66-87.

WMO-World Meteorological Organization. 2014. Statement on the status of the global climate in 2013. WMO. n. 1130. 